\title{
Rupture of Splenic Artery Aneurysm during Labor: A Case Report of Maternal and Fetal Survival
}

\author{
Fahad Al Asfar Mohamed Saber Piyaray M. Dhar Nema Al Awadhi \\ Department of Surgery, Al Adan Hospital, Ministry of Health, Kuwait
}

\section{Key Words}

Splenic artery aneurysm · Pregnancy

\begin{abstract}
Objective: To report a case of splenic artery aneurysm that ruptured during labor with both maternal and fetal survival. Clinical Presentation and Intervention: A 33year-old primigravida at 42 weeks of gestation was admitted to Adan Hospital for induction of labor. Three days after induction, the patient suddenly collapsed and was found to be hypotensive. Abruptio placentae was mistakenly diagnosed, despite the absence of vaginal bleeding, and the patient was immediately taken to the operating room for emergency cesarean section. A female infant was delivered without any evidence of abruptio placentae but with $2,000 \mathrm{ml}$ blood noted in the abdominal cavity. A vertical midline incision was performed and a ruptured splenic artery aneurysm was found. Proximal ligation of the splenic artery was performed followed by splenectomy. Both mother and newborn did well and were discharged on the 7th postoperative day. Conclusion: This case illustrates the need to consider ruptured splenic artery aneurysm as part of differential diagnosis of hemoperitoneum in pregnant women. Immediate surgical intervention is needed to ensure survival of both mother and fetus.
\end{abstract}

Copyright @ 2005 S. Karger AG, Base

\section{Introduction}

Rupture of a splenic artery aneurysm, although rare, is usually a catastrophic event associated with pregnancy. Ruptured splenic artery aneurysm during pregnancy usually has a fatal maternal and fetal outcome. It has been estimated that splenic artery aneurysm accounts for $60 \%$ of all reported cases of splanchnic artery aneurysm $[1,2]$.

\section{Case Report}

A 33-year-old primigravida at 42 weeks of gestation was admitted to the hospital for induction of labor by prostaglandins. Seventy-two hours after induction, the patient suddenly collapsed and was found to be hypotensive with a blood pressure of $80 / 60 \mathrm{~mm} \mathrm{Hg}$, a heart rate of 120 beats $/ \mathrm{min}$, and a respiratory rate of 30 breaths $/ \mathrm{min}$. Fetal heart beats were 80 beats $/ \mathrm{min}$.

Abdominal examination revealed generalized guarding. Immediate resuscitative measures were taken. The patient was provisionally diagnosed as having abruptio placentae, in spite of the absence of vaginal bleeding, and was immediately taken to the operating room for emergency cesarean section. In the operating room, the patient's blood pressure dropped to $60 / 40 \mathrm{~mm} \mathrm{Hg}$ with a pulse of 140 beats/ min in spite of aggressive resuscitation. Under general anesthesia the abdomen was entered through a Pfannenstiel incision. An estimated $2,000 \mathrm{ml}$ of blood was noted in the abdominal cavity. A low-transverse uterine incision was made, and a 3,000-gram female infant was delivered. The 1- and 5-min Apgar scores were 4 and 6, respectively. The placenta was manually removed and did not show any evidence of abruptio placentae. A vertical midline incision was performed in

\begin{tabular}{|c|c|}
\hline KARGER & $\begin{array}{l}\text { (C) 2005 S. Karger AG, Basel } \\
1011-7571 / 05 / 0141-0053 \$ 22.00 / 0\end{array}$ \\
\hline $\begin{array}{l}\text { Fax + 41613061234 } \\
\text { E-Mail karger@karger.ch } \\
\text { www.karger.com }\end{array}$ & $\begin{array}{l}\text { Accessible online at: } \\
\text { www. karger.com } / \mathrm{mpp}\end{array}$ \\
\hline
\end{tabular}

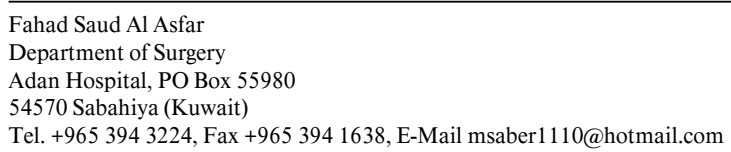


order to determine and control the source of intraperitoneal hemorrhage. A ruptured aneurysm was seen in the mid-portion of the splenic artery at the upper border of the pancreas. Proximal ligation of the splenic artery was performed to control bleeding from the ruptured aneurysm. This was followed by excision of the aneurysm and splenectomy. The uterine incision and abdominal incisions were closed. The patient received 12 units of packed red blood cells and 3 units of fresh frozen plasma. The mother tolerated the procedure well and had an uneventful recovery. Pneumovax was given to the mother. Both the mother and the newborn were discharged on the 7th postoperative day in good general condition.

\section{Discussion}

Maternal and fetal mortality of spontaneous rupture of a splenic artery aneurysm during pregnancy has been reported to be 75 and $95 \%$, respectively [3, 4]. It has been postulated that increased splenic artery blood flow and altered level of reproductive hormones affecting the elasticity of vascular tissues contribute to the rupture of splenic artery aneurysms in multiple pregnancies. Approximately $40 \%$ of women with splenic artery aneurysm are reported to be grand multiparous [1]. It has been suggested that the presence and risk of rupture of a splenic artery aneurysm may be seen in patients with $\alpha_{1}$-antitrypsin deficiency [5]. Clinical presentation is often nonspecific with rapid deterioration. Shock may be the initial presenting symptom. Double-rupture phenomenon has been described where bleeding is initially tamponaded by omentum or a blood clot that obstructs Winslow's foramen [6, 7]. Splenectomy for ruptured splenic artery aneurysm has been the most common form of surgical therapy [1].

Because of absent premonitory symptoms and signs in splanchnic arterial aneurysms, clinicians rarely recognize the condition preoperatively in spite of increasing reliance on abdominal ultrasonography, MRI or CT scan. Accordingly, rupture of a splenic artery aneurysm typically presents as sudden, unexpected obtundation or death [8]. Hence, if diagnosed before pregnancy, younger women need obliteration of the aneurysm before catastrophic rupture occurs during pregnancy and labor. It is emphasized that the chances of survival of the patient and the fetus depend considerably on early detection and rapid surgical intervention [9]. The best approach is diagnostic laparotomy. The survival of both mother and fetus in this case was due to the quick decision to do a rapid exploratory laparotomy, deliver the fetus quickly and control bleeding from the ruptured aneurysm. A pregnant woman who goes into shock without evidence of vaginal bleeding should be presumed to be bleeding internally and should undergo emergent laparotomy through a midline rather than a Pfannenstiel incision, as the bleeding is unlikely to be due to abruptio placentae. The hemorrhaging artery should be ligated first, followed by cesarean section and delivery of the fetus. We were fortunate to have the time to perform the cesarean section, deliver the fetus and still have time to ligate the splenic artery before the mother's demise.

\section{Conclusion}

This case shows that ruptured splenic artery aneurysm should be considered in the differential diagnosis of hemoperitoneum in a pregnant woman. Rapid surgical intervention is needed to ensure both maternal and fetal survival.

\section{References}

$>1$ Stanley JC, Fry WJ: Pathogenesis and clinical significance of splenic artery aneurysm. Surgery 1974;76:889-909.

2 Stanley JC, Zelenock GB: Splanchnic artery aneurysms; in Rutherford RD (ed): Vascular Surgery, ed 4. Philadelphia, Saunders, 1995, pp1124-1139.

$\checkmark 3$ Hillemanns P, Knitza R, Muller-Hocker J: Rupture of splenic artery aneurysm in a pregnant patient with portal hypertension. Am J Obstet Gynecol 1996;174:1665-1666.
4 Shahabi S, Jani J, Masters L, Cobin L, Greindl $\mathrm{J}$ : Spontaneous rupture of a splenic artery aneurysm in pregnancy: Report of two cases. Acta Chir Belg 2000;100:231-233.

5 Gaglio PJ, Regenstein F, Slakay D, Cheng S, Rinker R , Dick D: Alpha-1 antitrypsin deficiency and splenic artery aneurysm rupture: An association? Am J Gastroenterol 2001;95: 1531-1534.

6 de Vries JE, Shattenkerk ME, Malt RA: Complications of splenic artery aneurysm other than intraperitoneal rupture. Surgery 1982;91: 200-204.
7 O'Grady JP, Day EJ, Toole AL, Paust JC: Splenic artery aneurysm rupture in pregnancy. Obstet Gynecol 1977;50:627-630.

-8 Hunsaker DM, Turner S, Hunsaker JC 3rd: Sudden unexpected death resulting from splenic artery aneurysm rupture: Two case reports of pregnancy-related fatal rupture of splenic artery aneurysm. Am J Forensic Med 2002;23: 338-341.

9 Hunka D, Csordas T, Domany Z: Rupture of the splenic artery aneurysm during pregnancy. Acta Chir Hung 1991;32:77-82. 